(C) Copyright 2008 American Meteorological Society (AMS). Permission to use figures, tables, and brief excerpts from this work in scientific and educational works is hereby granted provided that the source is acknowledged. Any use of material in this work that is determined to be "fair use” under Section 107 of the U.S. Copyright Act September 2010 or that satisfies the conditions specified in Section 108 of the U.S. Copyright Act (17 USC §108, as revised by P.L. 94-553) does not require the AMS's permission. Republication, systematic reproduction, posting in electronic form, such as on a web site or in a searchable database, or other uses of this material, except as exempted by the above statement, requires written permission or a license from the AMS. Additional details are provided in the AMS Copyright Policy, available on the AMS Web site located at (http://www.ametsoc.org/) or from the AMS at 617-227-2425 or copyright@ametsoc.org. 


\title{
CLOUDSAT Adding a New Dimension to a Classical View of Extratropical Cyclones
}

\author{
by Derek J. Posselt, Graeme L. Stephens, and Martin Miller
}

Cloudsat probes the internal structure of frontal clouds and precipitation, and provides new perspective on a classical conceptual model.
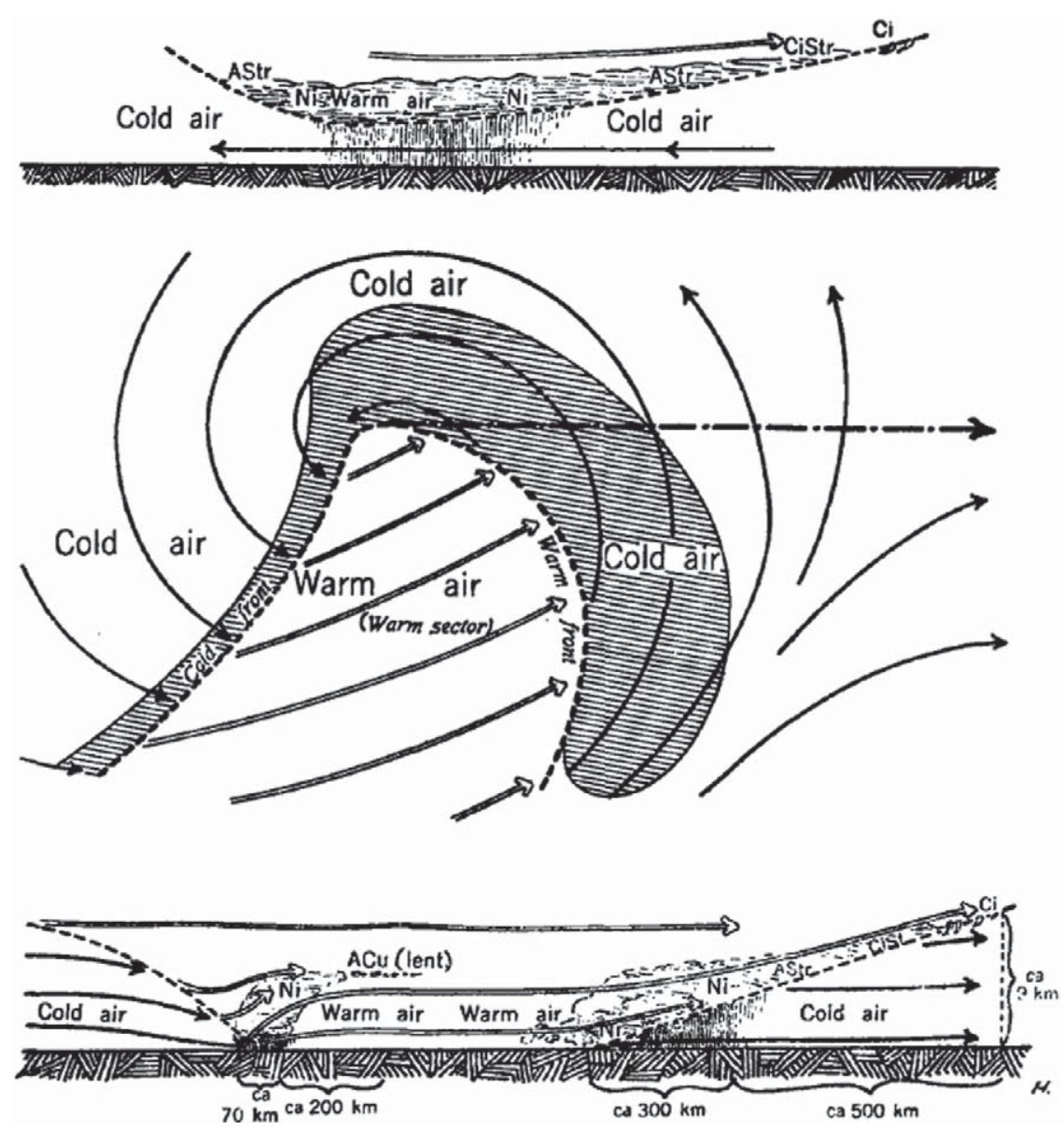

FIG. I. Illustration of frontal clouds and precipitation in the Norwegian Cyclone Model, as conceptualized in Bjerknes and Solberg (1922).

$\mathrm{E}$ xtratropical cyclones constitute some of the largest and most complex weather systems on our planet and play a key role in regulating Earth's energy balance, both through the meridional transport of energy from the equator to the poles, as well as through the effects of the clouds they produce on the climate system. In addition, midlatitude low pressure systems provide much of the precipitation received in the planet's temperate zones, and hence have an important effect on the availability of freshwater. Indeed, the earliest conceptual models of extratropical cyclone structure and development arose out of the need to understand patterns of rainfall, and over the past two 
centuries, research on extratropical cyclones has highlighted the continued need for understanding the distribution of clouds and precipitation associated with these storms.

During the mid- to late 1800s, an increased understanding of the thermodynamics of the atmosphere and, in particular, the energy released through the process of the condensation of water vapor, paved the way for one of the first conceptual models of the development of extratropical cyclones. In what has since been referred to as the thermal theory of cyclones (Kutzbach 1979), it was speculated that diabatic heating associated with widespread precipitation produced troposphere-deep ascending motion, leading to the low-level convergence and upper-level divergence that characterize midlatitude low pressure systems. By the turn of the century, an increasingly widespread observing network demonstrated the asymmetric nature of clouds, precipitation, and low-level circulation in low pressure systems, and conceptual models were modified accordingly. Though the understanding of the processes that drive extratropical cyclone development has continued to evolve, observations of the internal structure of frontal clouds and precipitation have been few and far between. With the addition of Cloudsat (Stephens et al. 2002) to the National Aeronautics and Space Administration's (NASA's) A-Train in April 2006, new and truly global observations of the internal structure of clouds and precipitation are now available. A few of the new insights that these observations provide on the structure of clouds in extratropical cyclones are highlighted in this paper.

\section{A BRIEF HISTORY OF EXTRATROPICAL CYCLONE RESEARCH FROM THE NORWEGIAN CYCLONE MODEL TO THE PRESENT. The advent of vertical soundings, coupled with the increased physical understanding}

AFFILIATIONS: Posselt-Department of Atmospheric, Oceanic and Space Sciences, University of Michigan, Ann Arbor, Michigan; StePHENS-Department of Atmospheric Science, Colorado State University, Fort Collins, Colorado; Miller-European Centre for Medium-Range Weather Forecasts, Reading, United Kingdom CORRESPONDING AUTHOR: Dr. Derek J. Posselt, 2455 Hayward Street, University of Michigan, Ann Arbor, MI 48I09-2I43 E-mail:dposselt@umich.edu

The abstract for this article can be found in this issue, following the table of contents.

DOI:10.1175/BAMS-89-5-599

In final form II October 2007

(C)2008 American Meteorological Society of atmospheric processes and the development of the telegraph network, culminated in the Norwegian Cyclone Model (NCM) in the early 1920s (Bjerknes and Solberg 1922; Fig. 1). ${ }^{1}$ This was the first conceptual model to document cyclone evolution from inception to decay. In addition, the NCM provided a remarkably accurate depiction of the three-dimensional structure of fronts, describing the near-discontinuous demarcation between different air masses, and giving a reasonable, albeit qualitative, explanation for the observed distribution of clouds and precipitation in midlatitude storms. Though attention quickly shifted from the analysis of rainfall to attempts to understand the origin and nature of the circulations observed in cyclones, a key component of the observational support for the NCM was the distribution of clouds and precipitation associated with cold, warm, and occluded fronts.

The rise of numerical models as tools for analysis and forecasting provided renewed impetus for the study of clouds and precipitation in extratropical cyclones in the middle of the twentieth century. These models allowed for the examination of the role of various physical processes in cyclone development, in particular, latent heat release and cloud effects on radiation. Multiple studies noted that latent heat release not only contributed to the intensity of low pressure systems and the rapidity of cyclogenesis (Smagorinski 1956; Krishnamurti 1968; Tracton 1973; Chang et al. 1982; Reed et al. 1988; Kuo et al. 1991; Davis 1992; Whittaker and Davis 1994; Stoelinga 1996), but also acted to change the spatial patterns of surface pressure and precipitation, as well as the structure and evolution of fronts (Baldwin et al. 1984; Dudhia 1993; Posselt and Martin 2004; Reeves and Lackmann 2004). It was also found that changes in the cloud effect on radiative fluxes could have a significant effect on the development of baroclinic waves. In particular, Simmons (1999) showed that an overproduction of upper-tropospheric cloudinduced cooling led to the anomalous enhancement of a simulated upper-level wave and the prediction of a strong cut-off low pressure system that was not

\footnotetext{
${ }^{1}$ Although Bjerknes and Solberg (1922) set out to describe the evolution of cyclones from inception to decay, the clouds and precipitation associated with fronts in the NCM are best shown in Fig. 1. Because the NCM assumed that the structure of the fronts did not change significantly during the cyclone life cycle, we will compare the clouds and precipitation in this figure with Cloudsat observations, but the reader should keep in mind the fact that extratropical cyclones and their associated fronts are evolving dynamical systems.
} 
subsequently observed. After decades of analysis, it is now well known that clouds, precipitation, and the associated latent heat release and effect on visible and infrared fluxes play a key role in cyclone formation and evolution. However, the specifics of the effect of clouds on extratropical cyclone dynamics is still not completely understood. This is, in part, due to the nonlinear feedback between latent heat release, radiation, and circulation, and also the fact that the fidelity of the numerical representations of clouds and precipitation critically depends on the model's physical parameterizations (Simmons 1999; Lackmann et al. 2002; Mahoney and Lackmann 2006).

Along with numerical models, observational studies have played a key role in understanding the distribution of clouds and precipitation in extratropical cyclones. Field experiments [e.g., the Fronts and Atlantic Storm Track Experiment (FASTEX); Joly et al. 1997, 1999] have revealed the tremendous range of cyclone features that exist in nature, as well as the high degree of spatial and temporal variability of clouds and precipitation. Conversely, satellite composites have been effectively used to aggregate observed cyclones into various categories, and have aided in the development of modern conceptual models (Lau and Crane 1995, 1997; Browning 1999; Tselioudis et al. 2000; Tselioudis and Rossow 2006; Field and Wood 2007). Though current observations can provide information on the extent of clouds for a range of cyclone types, to effectively assess the effects of clouds on cyclone evolution, it is essential to have information on the internal structure of clouds. It is the vertical distribution of condensate that determines the characteristics of the cloud radiative forcing, and lends insight into the vertical structure of condensational heating. Though highquality radar and dropsonde datasets were collected during FASTEX, and the Weather Surveillance Radar-1988 Doppler (WSR-88D) network provides near-continuous geographic and temporal coverage over the continental United States, truly global observations of the internal structure of clouds have thus far been lacking.

\section{CLOUDSAT CLOUD PROFILING RADAR AND AVAILABLE DATASETS. The Cloudsat} satellite was launched into orbit from Vandenburg Air Force Base on 28 April 2006, and the Cloudsat Cloud Profiling Radar (CPR) went into operational mode on 2 June 2006. In contrast to the ground-based WSR-88D [Next-Generation Weather Radar (NEXRAD)] radars operated by the National Weather Service, Cloudsat carries a nadir (downward)-pointing radar that operates at a wavelength of approximately $3 \mathrm{~mm}$ (94-GHz frequency). The relatively short wavelength (as compared with the $10 \mathrm{~cm}$ used for NEXRAD) and large range of sensitivity (from -30 to $+50 \mathrm{dBZ})^{2}$ is designed to allow the CPR to observe a wide range of cloud types and thicknesses. The radar has a footprint that measures $1.4 \mathrm{~km}$ across track by $3.5 \mathrm{~km}$ along track at the surface, with a pulse width of $3.3 \mu$ s (pulserepetition frequency of $4,300 \mathrm{~Hz}$ ) and vertical range bins of $250 \mathrm{~m}$. Data are averaged every $0.16 \mathrm{~s}$ along track, are quality controlled, and can be obtained online from the Cloudsat data processing center. Temperature, water vapor, and ozone profiles from the European Centre for Medium-Range Weather Forecasts (ECMWF) operational analysis are time and space interpolated to the Cloudsat track, and top-of-the-atmosphere visible and infrared radiances from channels 20 and 27-36 on the Aqua Moderate-Resolution Imaging Spectroradiometer (MODIS) instrument are matched to Cloudsat CPR data. In addition to radar reflectivity, a growing number of retrieved cloud parameters are computed and archived as part of the Cloudsat dataset; these include cloud classification, cloud liquid and ice water content, cloud optical depth, and long- and shortwave radiative fluxes and heating rates. [For a detailed description of each dataset available in the Cloudsat data stream, the reader is referred to the online Cloudsat Data Processing Center (www. cloudsat.cira.colostate.edu/index.php).]

In the analysis presented below, the Cloudsat 2B-GEOPROF (Mace et al. 2007, hereafter MAC) and ECMWF ancillary (ECMWF-AUX) datasets are used to construct cross sections, and ECMWF global analyses at $0.5^{\circ}$ resolution are used to construct plan views. Precipitation rate is derived from measured CPR attenuation (Haynes and Stephens 2007). Because this is a relatively new technique, and because the Cloudsat precipitation retrievals have not been extensively tested, we will depict the precipitation rate as being either light $\left(<1 \mathrm{~mm} \mathrm{~h}^{-1}\right)$, moderate $\left(1-5 \mathrm{~mm} \mathrm{~h}^{-1}\right)$, or heavy $\left(>5 \mathrm{~mm} \mathrm{~h}^{-1}\right)$. We also note that, although the effects of surface clutter above $500 \mathrm{~m}$ from the surface have been removed in the latest version of 2B-GEOPROF (version R04), for

\footnotetext{
${ }^{2}$ Negative $\mathrm{dBZ}$ values result from the fact that the reflectivity factor is proportional to the log of the signal received at the radar. Negative reflectivities simply mean that the observed cloud is not reflecting much of the radar signal, which typically means that the cloud particles are small and/or that the cloud is not very thick.
} 
reasons discussed in MAC the presence of surface clutter in earlier versions of the CPR data restricts the use of Cloudsat radar reflectivity to regions above $1 \mathrm{~km}$ above the Earth's surface.

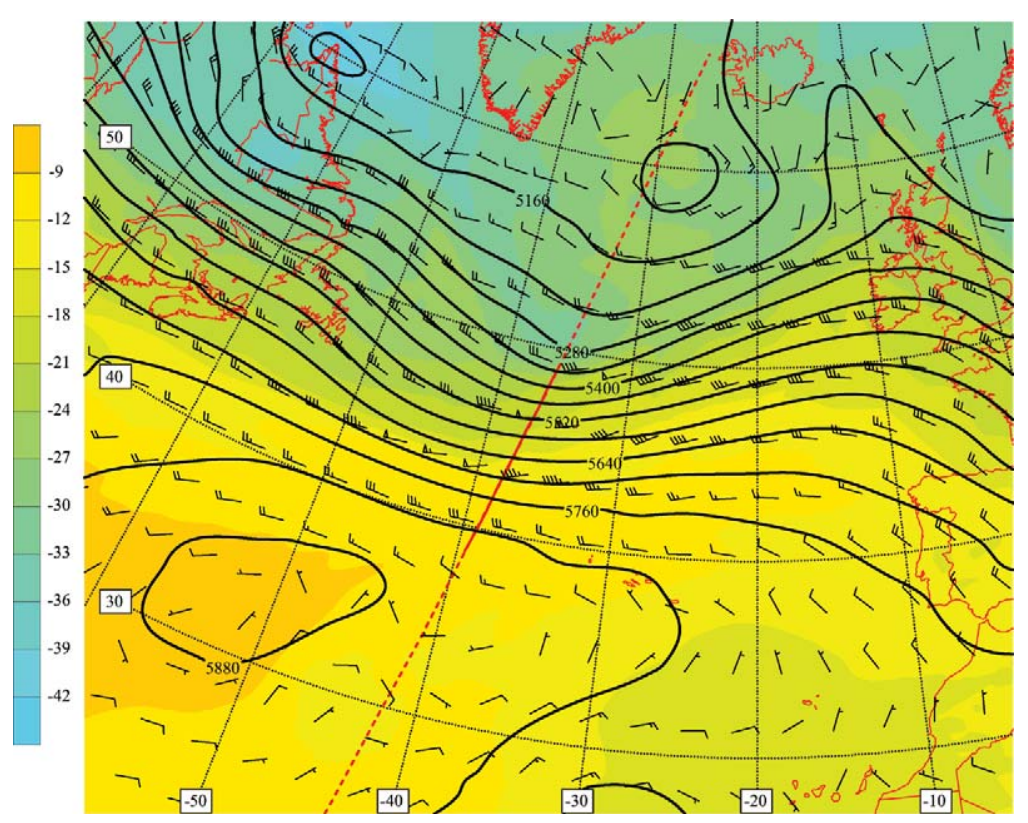

FIG. 2. Depiction of 500-hPa geopotential height ( $\mathrm{m}$, solid black lines), temperature $\left({ }^{\circ} \mathrm{C}\right.$, color shaded), and winds (kt, barbs) for the ECMWF analysis valid 0600 UTC 22 Nov 2006. A portion of the Cloudsat ground track from granule 3026 is depicted in the reddashed line, and the portion of the track that corresponds to the cross section in Fig. 4 is shown in solid red.

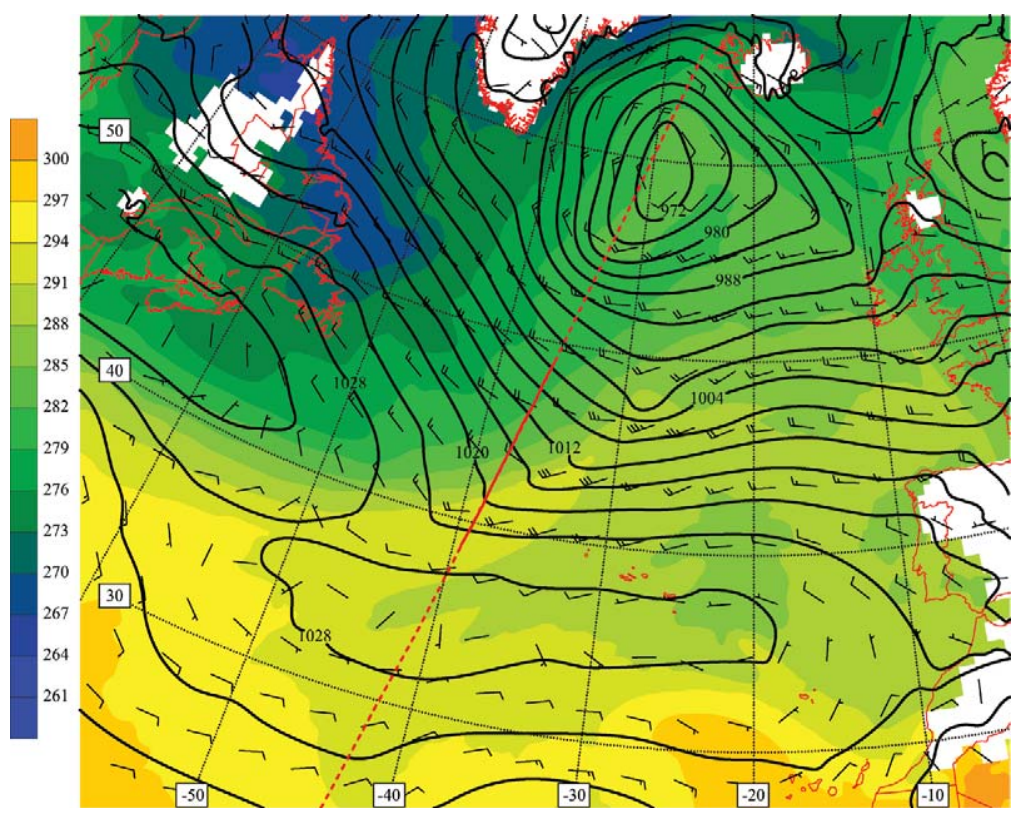

FIG. 3. Depiction of mean sea level pressure (hPa, solid black contours) with $950-\mathrm{hPa}$ potential temperature (K, color shaded) and winds (kt, barbs) for the ECMWF analysis valid 0600 UTC 22 Nov 2006. As in Fig. 2, the Cloudsat ground track is shown in the red solid and dashed lines.

\section{CLOUDSAT OBSERVATIONS OF FRONTAL} CLOUDS AND PRECIPITATION. To demonstrate the facility of Cloudsat for observing clouds and precipitation in frontal zones, we present three distinct cases in which Cloudsat intersected a frontal feature in a North Atlantic oceanic cyclone. Though a vast array of different observed and simulated mesoscale extratropical frontal features have been reported in the literature, cold, warm, and occluded fronts are the three key features of the NCM, and we make these the focus of our analysis here. In the discussion that follows, we examine each type of front in light of the NCM, and characterize the distribution of clouds and precipitation as viewed from Cloudsat.

As we mentioned above, output from numerical models is often used to diagnose the physical processes associated with observed cyclone features. Observations, in turn, are used to evaluate the performance of models, and lead to improvements in their ability to realistically represent the real world. Because Cloudsat observes the details of the internal structure of clouds, it offers a unique opportunity to assess modelsimulated clouds and precipitation. Hence, for each case described below, we demonstrate how Cloudsat can be used to evaluate numerical representations of clouds and precipitation. Specifically, we use the radar simulator package described in Haynes et al. (2007) to compute Cloudsat radar reflectivity from ECMWF-analyzed cloud liquid and ice content fields, and then compare the result with that which Cloudsat observed. It should be noted at the outset that 1) the ECMWF fields used in the comparison were gridded at a coarser resolution than is used in the operational model, and 2) falling precipitation was not available in the analysis datasets. Consequently, the comparisons documented below should be viewed as being strictly qualitative in nature. 
Cold front: 0600 UTC 22 November 2006. The first case is a trailing cold front that exists as part of a decaying extratropical cyclone located southwest of Iceland at approximately 0600 UTC 22 November 2006. Plots of the $500-\mathrm{hPa}$ geopotential height, winds, and temperature (Fig. 2) depict a broad upper-level low pressure system with two distinct embedded shortwaves. Examination of the mean sea level pressure distribution (Fig. 3) indicates a storm that is well occluded with the surface low pressure center located directly beneath the upper-level low, and with the center of lowest pressure at the surface well separated from the intersection of cold and warm fronts. The cold front is clearly visible at low levels as an enhanced potential temperature gradient with an attendant wind shift and a distinctive kink in the mean sea level pressure isobars. The Cloudsat track is shown in the dashed red line in both figures, and can be seen to cross the front at approximately $41^{\circ} \mathrm{N}$ latitude and $37^{\circ} \mathrm{W}$ longitude.

The observed CPR reflectivity along the segment of the track that immediately intersects the cold front (depicted in the solid line in Figs. 2 and 3) is shown in Fig. 4a, and is overlaid with contours of equivalent potential temperature computed from the ECMWF analysis. ${ }^{3}$ The cross section reveals a classic cold-frontal structure, with an enhanced thermal-moisture gradient at the frontal boundary, decreased thermal stratification ahead of the front, and increased stratification behind. Shallow convection can be observed in the cold and relatively unstable air to the north of the front, as can the deep convection associated with the narrow region of instability at the front's leading edge. A comparison with Fig. 1 reveals that the general cloud distribution is reasonably similar to that of the NCM cold front, with deep convection in a region approximately $100 \mathrm{~km}$ wide at the front's leading edge, and cirrus aloft that extends to a distance of approximately $300 \mathrm{~km}$ from the surface front. However, while the NCM realistically represents the form of the observed cloud, the Cloudsat radar reflectivity reveals additional details

\footnotetext{
${ }^{3}$ Fronts are characterized by large horizontal contrasts in temperature; however, fronts are often difficult to identify in temperature cross sections. If there is no latent heat release (e.g., from condensation), the potential temperature does not change following the motion and can therefore be effectively used to identify the boundary that separates air from two differing source regions. For this reason, potential temperature is often used to show the location of a front (Wallace and Hobbs 1977, 135-136). We use equivalent potential temperature in our cross sections because it is conserved even in the presence of latent heat release, and includes information on the water vapor content of the air. As such, it provides a clear depiction of frontal temperature and moisture contrasts in areas with actively precipitating cloud systems.
} 
of the internal structure of the cloud. Note the presence of multiple precipitating low-level convective showers in the cold air behind (to the north of) the front, as well as the presence of small-scale regions of more intense reflectivity embedded within the region of deep convection. It is particularly interesting that the regions of the largest reflectivity just to the north of the surface front are not uniformly associated with the largest precipitation rates, which is an indication

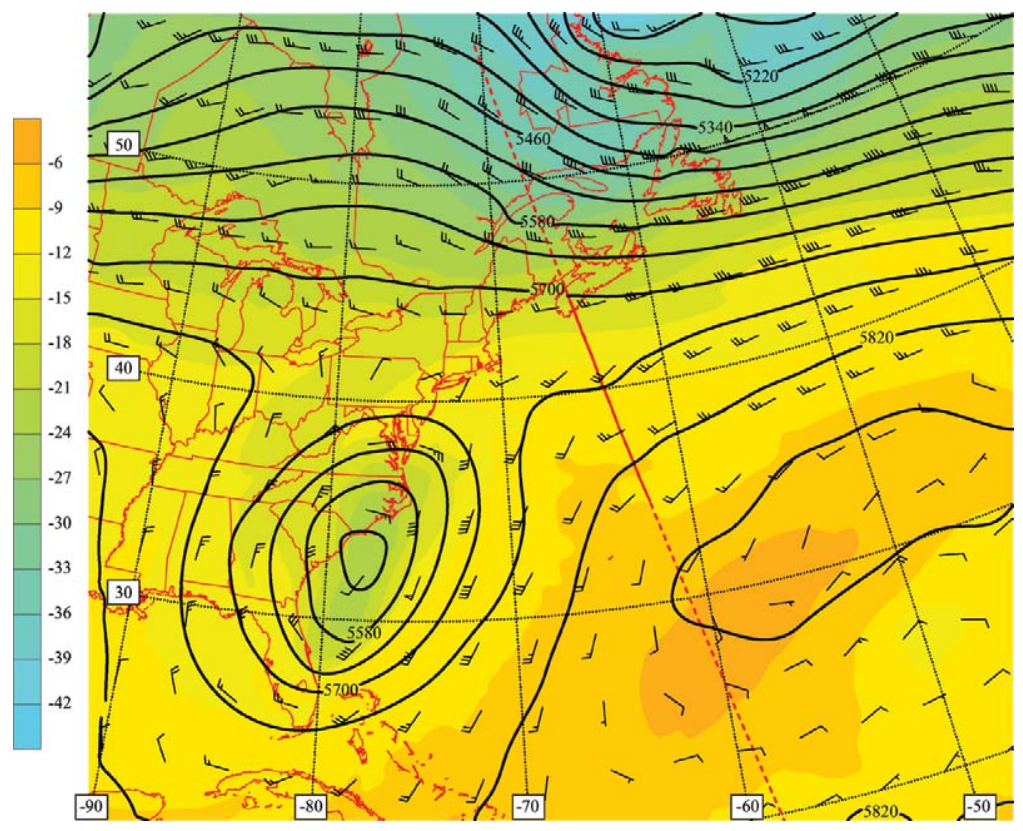

Fig. 5. As in Fig. 2, but for the analysis valid I800 UTC 22 Nov 2006 and for a portion of the Cloudsat track from granule 3034 .

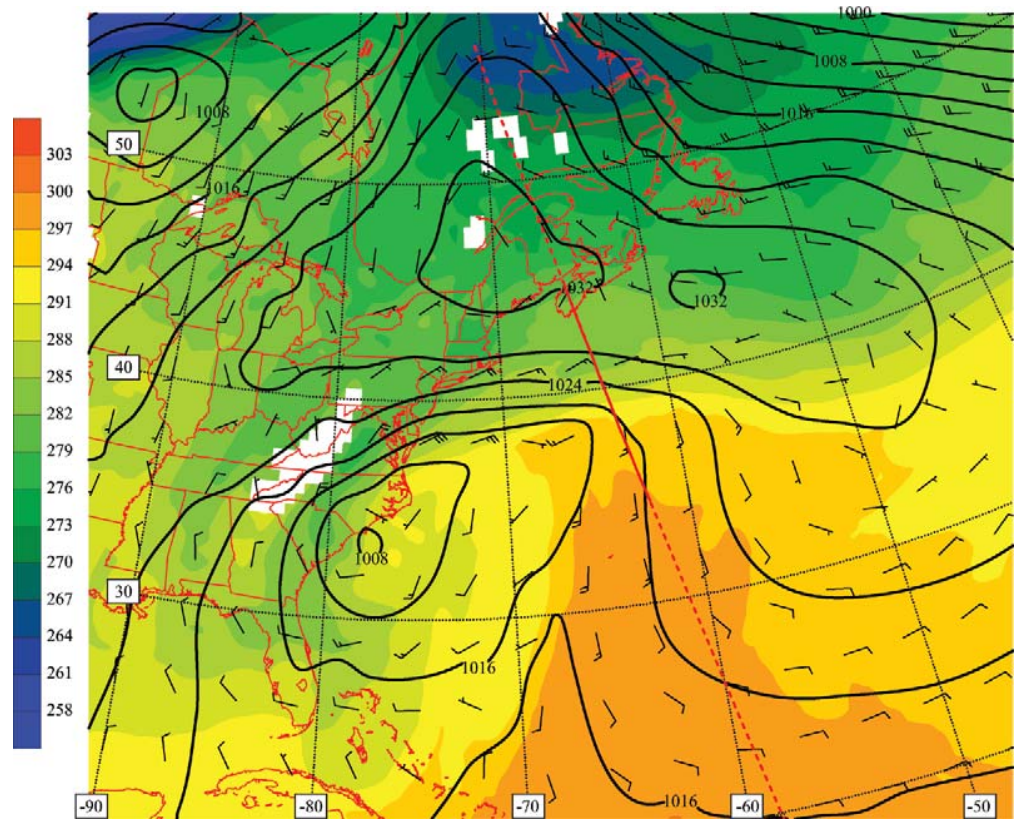

FIG. 6. As in Fig. 3, but for analysis valid 1800 UTC 22 Nov 2006 and for a portion of the Cloudsat track from granule 3034 . that there is an abundance of relatively large particles suspended in this region. It is also interesting that the cirrus cloud content does not decrease smoothly with increasing distance south of the front, but instead exhibits pockets of relatively high reflectivity, possibly indicating the presence of multicellular or episodic convection. Note also that a majority of the widespread shallow convective clouds embedded in the weakly stratified cold air behind the front appear to be producing precipitation at the surface. These clouds are commonly found in the cold air behind a cold front, particularly in oceanic cyclones, and were not described in the NCM.

Reflectivity simulated from ECMWF clouds is shown in Fig. $4 \mathrm{~b}$. While the model representation clearly suffers from the relatively coarse nature of the gridded analysis $\left(0.5^{\circ} \times 0.5^{\circ}\right.$ in the horizontal $)$, the general cold-frontal cloud structure is represented quite well. The primary difference appears to be the absence of discrete pockets of enhanced reflectivity in the simulated convection and cirrus, which may be due to the coarse analysis grid. In addition, there is an anomalously large reflectivity in the simulated prefrontal low cloud, and the post-frontal shallow convection is not effectively resolved by the model.

Warm front: 1800 UTC 22 November 2006. It is relatively common for cyclones over the North Atlantic to exhibit upstream development (Simmons and Hoskins 1979; Thorncroft and Hoskins 1990; Orlanski and Chang 1993; Decker and Martin 2005; Mailier et al. 2006), and in the case examined above, the trailing cold baroclinic zone was associated with another developing wave to its southwest located near the east coast of North America. As of 1800 UTC, the upperlevel circulation associated with this storm was cut off from the main upper-level flow (Fig. 5), and was located just off of the coast of South Carolina. At low levels (Fig. 6), a 
relatively weak low pressure center can be seen directly beneath the upper-level low, with a warm-frontal structure that stretched from Cape Hatteras east-northeast into the Atlantic Ocean. At this time, the front can be clearly identified in the strong lowlevel thermal gradient, as well as in the kinked sea level pressure isobars, and in the low-level wind shift. An examination of the CPR radar reflectivity and ECMWF equivalent potential temperature (Fig. 7a) reveals a broad area of cloud and precipitation along and ahead of the warm front itself. The warm edge of the front is clearly evident in the thermal-moisture contrast at approximately $39^{\circ} \mathrm{N}$ latitude, as is the classic sloping distribution of the cloud, which thins with increasing vertical and horizontal distance, starting approximately $300 \mathrm{~km}$ north of the surface front. In addition to the physical thinning of the cloud, there is a pronounced decrease in reflectivity with increasing distance from the surface front, indicating an associated decrease in cloud liquid and ice water content.

Though the general distribution of clouds along the warm front resembles those in the NCM, Cloudsat reveals details not seen in the Norwegian model. Specifically, the cloud top slopes upward with height in the NCM, while the observed cloud-top height remains relatively constant. In addition, large variability in the reflectivity (and, by association, the cloud water content) is visible, as is the presence of embedded regions of enhanced reflectivity inside the cloud, which are generally associated with increased precipitation rate at the surface. Note also the enhanced region of reflectivity that persists near the base of the cloud with increasing distance from the warm front, which is an indication that large ice particles are settling into the lower regions of the cloud. ${ }^{4}$
It is interesting to note the extensive region of cloud to the south of the surface warm front, which is likely associated with ascending motion near the intersection of warm and cold fronts at low levels, and is embedded in a region of weak static stability. This region is producing less precipitation than the cloudy region that is directly on top of the warm front, though the values of reflectivity are similar. Examination of the three-dimensional wind field from the ECMWF analysis (not shown) reveals this to be part of the warm conveyor belt airstream (Harrold 1973; Wernli and Rossa 1994; Browning 1999), which had not yet been identified at the time of the NCM, but has been well described since.

Examination of simulated reflectivity fields (Fig. 7b) reveals that, as in the cold-frontal case, the distribution of the clouds in the region around the front is well represented in the analysis. The notable exception is the lack of reflectivity below the $5-\mathrm{km}$ level to the north and south of the surface front. It is possible that this discrepancy is due to the lack of suspended precipitation in the analysis; rain is

\footnotetext{
${ }^{4}$ Although regions of enhanced reflectivity are often observed in regions where precipitating ice particles are melting (the "bright band"), analysis of the cross section of analyzed temperature (not shown) reveals in-cloud temperatures north of $42^{\circ} \mathrm{N}$ latitude to be uniformly $-10^{\circ} \mathrm{C}$.
} 
assumed to fall out of the atmosphere immediately in the model.

Occlusion: 0600 UTC 5 December 2006. Perhaps the most strongly debated component of the NCM is its description of the occlusion process, which describes the formation of an occluded front as the cold front that overtakes and intersects the warm front. At approximately 0600 UTC 5 December 2006, Cloudsat intersected the occluded sector of a mature cyclone off the east coast of North America. This storm was associated with a shortwave trough over Nova Scotia, Canada, that was embedded in a larger region of low pressure aloft (Fig. 8), centered over far northern Quebec, Canada. Though the upper-level shortwave trough is relatively innocuous in appearance, there is a deep surface disturbance at this time (Fig. 9), with a minimum central pressure of $972 \mathrm{hPa}$ and a well-developed 950-hPa thermal ridge. The low-level baroclinic zones exhibit evidence of the frontal fracture process described by Shapiro and Keyser (1990), with a noticeable weakening in the potential temperature gradient at the northern portion of the cold front, and with the strongest thermal contrast located north and east of the cyclone center in the occluded sector. Cloudsat intersected the occluded sector near the cyclone center at approximately this time, and the cross section along a portion of the Cloudsat track is depicted in Fig. 10a. It is immediately apparent that the observed distribution of clouds differs markedly from the NCM; in the NCM, clouds are located in the warm air that has been forced upward by the intersection of fronts (Fig. 1). In this case, the cloud distribution is consistent with the Shapiro and Keyser conceptual model; both the cloud field and thermal structure exhibit characteristics that are similar to those of the warm front in Fig. 7a, with decreased thermal stratification ahead of the surface front and a gradually sloping distribution of cloud that begins to decrease in thickness approximately $300 \mathrm{~km}$ north of the front's leading edge. The distribution of precipitation associated with this cloud feature is qualitatively similar to that of the warm front above (Fig. 7a), but we note that the precipitation rate is lower in this case. It is interesting to note that, in contrast to the warmfrontal case, there is a narrow band of shallow convection near the 
southern edge of the front that is producing relatively intense precipitation. Note also the presence of shallow convection to the north of the front; as in the cold-frontal case (Fig. 4a), the majority of these clouds appear to be producing precipitation. A comparison of Cloudsat (Fig. 10a) and simulated ECMWF (Fig. 10b) reveals, as in the cold- and warm-frontal cases described above, a very realistic distribution of cloud in the analysis. The primary difference can be found at the low levels to the north of the front, where the observed reflectivity is much larger than that in the model. As with the warm-frontal case, this may be due to precipitation that is falling in nature, but immediately falls out of the model. It is interesting that, though the convection associated with the surface front is occurring on a scale much smaller than that of the model grid, the model still generates realistically large reflectivity values in this region.

Each of the cases described above illustrates the utility of Cloudsat for examining features of midlatitude storms, because the reflectivity data offer the opportunity to evaluate the vertical and horizontal distribution of clouds associated with conceptual and numerical models, and to examine the meso- and microscale details of cloud internal structure.

SUMMARY. The study of extratropical cyclone structure and development has a long and rich history, and, though the science is mature, many interesting research questions remain. Many of these center around the distribution of clouds and precipitation produced by these storms, as well as the feedback from cloud radiative forcing and the latent heat release to cyclone structure and dynamics. In this paper, we have looked at clouds and precipitation in midlatitude cyclones from a historical perspective, comparing modern observations of frontal clouds from Cloudsat with those depicted in the Norwegian Cyclone Model. We demonstrated that, though observed clouds bear a remarkable similarity to those in the NCM, Cloudsat reveals intriguing details about cloud internal structure. Following comparisons with the NCM, observations from Cloudsat were used to evaluate a numerical representation of frontal clouds and precipitation, and it was shown that Cloudsat can serve as a potent tool for model assessment. The analysis presented in this paper demonstrates that, because Cloudsat provides global observations of the internal structure of clouds, it is poised to add a key observational component to the rich tradition of research into extratropical features and evolution.

In closing, we would like to point out that, though the ECMWF analysis matched the Cloudsat observations quite well in each of the cases shown above, care must be taken when comparing an instrument with a very narrow swath width with model data gridded at much coarser resolution. First, there is the problem of representativeness, in which features observed by Cloudsat may not be indicative of the larger-scale cloud structure. In addition, cloud fields in the model are assumed to be averaged over an entire grid box, and hence comparisons certainly suffer from lack of treatment of subgrid variability. This is especially pronounced in the case of radar, in which the reflectivity is proportional to the sixth power of the 
particle diameter. Finally, the comparison takes no account of errors in the positioning of features; if the cyclone structure is correctly simulated in the model, but is not positioned correctly in space or time, the comparison might yield quite different results (Rife and Davis 2005). In the above cases, the problems of representativeness and positioning were minimized through the examination of Cloudsat tracks that intersected fronts either at or near perpendicular to the leading edge, but this issue must be accounted for in systematic comparison studies.

As a final note, we would like to point out that Cloudsat does not operate in isolation, but instead is embedded in the larger A-Train constellation of satellites, each of which is designed to provide a unique piece of information on the distribution of temperature, water vapor, clouds, and precipitation, as well as atmospheric chemistry. Taken together with Cloudsat, measurements from the A-Train as a whole yield a rich dataset of cloud, thermodynamic, and moisture information.

ACKNOWLEDGMENTS. The authors wish to thank Mr. John Haynes for providing the Cloudsat radar simulator and precipitation datasets, and Mr. Phillip Partain for his assistance obtaining the Cloudsat and ECMWF analysis datasets. Dr. Angela Benedetti helped with coupling the ECMWF cloud fields with the Cloudsat radar simulator. The comments of two anonymous reviewers were extremely helpful in refining the content of both the manuscript and figures. This work was funded under NASA NMP Contracts NAS5-99237, NNG06GB416, and NNG06GC10G.

\section{REFERENCES}

Baldwin, D., E.-Y. Hsie, and R. A. Anthes, 1984: Diagnostic studies of a two-dimensional simulation of frontogenesis in a moist atmosphere. J. Atmos. Sci., 41, 2686-2700.

Bjerknes, J., and H. Solberg, 1922: Life cycle of cyclones and the polar front theory of atmospheric circulation. Geophys. Publ., 3, 1-18.

Browning, K. A., 1999: Mesoscale aspects of extratropical cyclones: An observational perspective. The Lifecycles of Extratropical Cyclones, M. A. Shapiro and S. Gronas, Eds., Amer. Meteor. Soc., 265-283.

Chang, C. B., D. J. Perkey, and C. W. Kreitzberg, 1982: A numerical case study of the effects of latent heating on a developing wave cyclone. J. Atmos. Sci., 39, 1555-1570.

Davis, C. A., 1992: A potential vorticity analysis of the importance of initial structure and condensational heating in observed cyclogenesis. Mon. Wea. Rev., 120, 2409-2428.

Decker, S. G., and J. E. Martin, 2005: A local energetics analysis of the life cycle differences between consecutive, explosively deepening, continental cyclones. Mon. Wea. Rev., 133, 295-316.

Dudhia, J., 1993: A nonhydrostatic version of the Penn State-NCAR Mesoscale Model: Validation tests and simulation of an Atlantic cyclone and cold front. Mon. We. Rev., 121, 1493-1513.

Field, P. R., and R. Wood, 2007: Precipitation and cloud structure in midlatitude cyclones. J. Climate, 20, 233-254.

Harrold, T. W., 1973: Mechanisms influencing the distribution of precipitation within baroclinic disturbances. Quart. J. Roy. Meteor. Soc., 99, 232-251.

Haynes, J., and G. L. Stephens, 2007: Tropical oceanic cloudiness and the incidence of precipitation: Early results from CloudSat. Geophys. Res. Lett., 34, L09811, doi:10.1029/2007GL029335.

_-, R. T. Marchand, Z. Luo, A. Bodas-Salcedo, and G. L. Stephens, 2007: A multipurpose radar simulation package: QuickBeam. Bull. Amer. Meteor. Soc., 88, 1723-1727.

Joly, A., and Coauthors, 1997: The Fronts and Atlantic Storm-Track Experiment (FASTEX): Scientific objectives and experimental design. Bull. Amer. Meteor. Soc., 78, 1917-1940.

—- and Coauthors, 1999: Overview of the field phase of the Fronts and Atlantic Storm-Track Experiment (FASTEX) project. Quart. J. Roy. Meteor. Soc., 125, 3131-3163.

Krishnamurti, T. N., 1968: A study of a developing wave cyclone. Mon. Wea. Rev., 96, 208-217.

Kuo, Y.-H., M. A. Shapiro, and E. G. Donall, 1991: The interaction between baroclinic and diabatic processes in a numerical simulation of a rapidly intensifying extratropical marine cyclone. Mon. Wea. Rev., 119, 368-384.

Kutzbach, G., 1979: The Thermal Theory of Cyclones: A History of Meteorological Thought in the 20th Century. Amer. Meteor. Soc., 255 pp.

Lackmann, G. M., K. Keeter, L. G. Lee, and M. B. Ek, 2002: Model representation of freezing and melting precipitation: Implications for winter weather forecasting. Wea. Forecasting, 17, 1016-1033.

Lau, N.-C., and M. W. Crane, 1995: A satellite view of the synoptic-scale organization of cloud properties in midlatitude and tropical circulation systems. Mon. Wea. Rev., 123, 1984-2006.

—, and _-, 1997: Comparing satellite and surface observations of cloud patterns in synoptic-scale circulation systems. Mon. Wea. Rev., 125, 3172-3189. 
Mace, G. G., R. Marchand, Q. Zhang, and G. L. Stephens, 2007: Global hydrometeor occurrence as observed by CloudSat: Initial observations from summer 2006. Geophys. Res. Lett., 34 (9), L09808, doi:10.1029/2006GL029017.

Mahoney, K. M., and G. M. Lackmann, 2006: The sensitivity of numerical forecasts to convective parameterization: A case study of the 17 February 2004 east coast cyclone. Wea. Forecasting, 21, 465-488.

Mailier, P. J., D. B. Stephenson, C. A. T. Ferro, and K. I. Hodges, 2006: Serial clustering of extratropical cyclones. Mon. Wea. Rev., 134, 2224-2240.

Orlanski, I., and E. K. M. Chang, 1993: Ageostrophic geopotential fluxes in downstream and upstream development of baroclinic waves. J. Atmos. Sci., 50, 212-225.

Posselt, D. J., and J. E. Martin, 2004: The role of latent heat release in the formation of a warm occluded thermal structure. Mon. Wea. Rev., 132, 578-599.

Reed, R. J., A. J. Simmons, M. D. Albright, and P. Unden, 1988: The role of latent heat release in explosive cyclogenesis: Three examples based on ECMWF operational forecasts. Wea. Forecasting, 3, 217-229.

Reeves, H. D., and G. M. Lackmann, 2004: An investigation of the influence of latent heat release on coldfrontal motion. Mon. Wea. Rev., 132, 2864-2881.

Rife, D. L., and C. A. Davis, 2005: Verification of temporal variations in mesoscale numerical wind forecasts. Mon. Wea. Rev., 133, 3368-3381.

Shapiro, M. A., and D. Keyser, 1990: Fronts, jet streams, and the tropopause. Extratropical Cyclones, The Erik Palmen Memorial Volume, C. W. Newton and E. O. Halopainen, Eds., Amer. Meteor. Soc., 167-191.

Simmons, A. J., 1999: Numerical simulations of cyclone life cycles. The Lifecycles of Extratropical Cyclones, M. A. Shapiro and S. Gronas, Eds., Amer. Meteor. Soc., 123-137.

— , and B. J. Hoskins, 1979: The downstream and upstream development of unstable baroclinic waves. J. Atmos. Sci., 36, 1239-1254.

Smagorinski, J., 1956: On the inclusion of moist adiabatic processes in numerical prediction models. Ber. Dtsch. Wetterdienstes, 5, 82-90.

Stephens, G. L., and Coauthors, 2002: The CloudSat Mission and the A-Train: A new dimension of spacebased observations of clouds and precipitation. Bull. Amer. Meteor. Soc., 83, 1771-1790.

Stoelinga, M. T., 1996: A potential vorticity-based study of the role of diabatic heating and friction in a numerically simulated baroclinic cyclone. Mon. Wea. Rev., 124, 849-874.
Thorncroft, C. D., and B. J. Hoskins, 1990: Frontal cyclogenesis. J. Atmos. Sci., 47, 2317-2336.

Tracton, M. S., 1973: The role of cumulus convection in the development of extratropical cyclones. Mon. Wea. Rev., 101, 573-592.

Tselioudis, G., and W. B. Rossow, 2006: Climate feedback implied by observed radiation and precipitation changes with midlatitude storm strength and frequency. Geophys. Res. Lett., 33, L02704, doi:10.1029/2005GL024513.

— , Y. C. Zhang, and W. B. Rossow, 2000: Cloud and radiation variations associated with northern midlatitude low and high sea level pressure regimes. $J$. Climate, 13, 312-327.

Wallace, J. M., and P. V. Hobbs, 1977: Atmospheric Science an Introductory Survey. Academic Press, 467 pp.

Wernli, H., and A. M. Rossa, 1994: Identification of structures within extratropical cyclones based on objective criteria. Proc. Int. Symp. on the Lifecycles of Extratropical Cyclones, Vol. II, Bergen, Norway, 548-553.

Whittaker, J. S., and C. A. Davis, 1994: Cyclogenesis in a saturated environment. J. Atmos. Sci., 51, 889-907. 